\title{
Meta Principalism: Simple Guiding Concept for Self Preparation of Private School Principal of Nepal
}

\author{
Babin Pokharel \\ Kathmandu University School of Education, Nepal \\ babinpokharel@gmail.com
}

\begin{abstract}
A school leader of the today's world possesses a vast array and network of skills. The $21^{\text {st }}$ century principal has knowledge of and appreciation for the educational system, has a strong foundation and diverse repertoire of skills and strategies, which are theoretically based, and develops and maintains trusting, positive and supportive relationships. In order to be a changed principal required by $21^{\text {st }}$ century, all of these traits, skills, behaviors and situational factors need to be attached together, in order to understand and appreciate the big picture in terms of viewing the principal as an educational leader and change agent. Simple guiding principal of Meta principalism gives a clear concept of principalism required for $21^{\text {st }}$ century. I found out that school principal makes a difference in school and student performance if they are granted the autonomy to lead in more transformative way. Their skills and knowledge for different leadership styles, teamwork, and monitoring, of instructional and administrative functions makes them qualified to perform par excellence in leading private school of Nepal. Hence, Meta principalism brings leadership preparation and training into new meanings which are central force of private schools of Nepal to stimulate and spread innovation and to develop effective and self prepared principal that can bring substantial benefits to both schools and community.
\end{abstract}

Keywords: Principal, preparation, transformation, change, leadership

\section{Introduction}

Conventional leadership, which is, I found profoundly rooted in private school in Nepal which is insufficient to meet the demands of today's world. As we have already entered the new millennium, our world is characterized by unprecedented complexity, paradox, and unpredictability. For me, change is rapid and relentless. The magnitude and speed of change will continue (Conner, 1995). Today's school principal face demands unlike any ever before faced. Standard and conventional leadership approaches that many of the private school principal in Nepal has served them well long time back are quickly becoming burden. Conservative insight regarding leadership and many of its habits must be unlearned. The principles of effective change management that are necessary in effective running of school also have been well described by Fullan (1993), who identifies three essential processes. The first is the need to understand the school's current culture, because I think without this understanding there will be little if any appreciation of what is worth preserving and what urgently needs changing to ensure growth and development (Fullan, 1993). Hargreaves (1999) provides a very useful and practical framework for identifying school culture. The second vital element in the change process is the effective leadership of the head teacher, which serves as the initial inspiration and the driving catalyst for change and development. The third and final element is what is described as the process of reculturing - of gradually transforming the overall culture or ethos of the school. The strong trust charisma, and independent leader and transforming leadership are gradually rooting in Nepalese school scenario, which strived to be proven as counter-productive in the new millennium and undermine a sustainable future. Mutual trust between school leaders and teaching staff is the single most important factor within a school's culture that will allow for successful changes for improvement to be possible. Reculturing or cultural transformation requires both the establishment of appropriate structures and systems to support the change process, and the effective management and development of people within the organization (Kotter, 1996). Without trust, I feel there is no effective communication or teamwork, which hinder the expansion of commitment to school improvement and reculturing of school. The challenges and opportunities of principal preparation process for a new type of school principal, obviously completely new and extra way of thinking about leadership and of developing future principal. 
Nepalese private school principal has to explore the nature of the innovation in leading and leadership qualities and capabilities expected to be crucial in the future school transformation. As I have already explained a significant numbers of gap remains between the advanced countries and Nepal, in many ways private school principal of Nepal lacks current leadership competencies needed in the future. Meta Principalism highlights on leading and guiding others in school change by taking risks but not carelessly or without forethought. Furthermore Meta Principalism encourages the major actor principal to move further to tackle school transformation that leads school effectiveness in very simple steps. Leaders of change provide the needed stimulus for change which is a must for $21^{\text {st }}$ century. Calling attention to all the possibilities that they need to be self prepared, they take risks and encourage others to initiate change. I do support that school Principal get prepared by encouraging their staff to experiment with various transformational methods to meet the academic needs of the students and bring school into new height together with self preparation. Although Nepalese principal maintains values and ethics of leadership while striving to develop and sustain trusting, positive, and supportive relationships with students, parents, staff and members of the community, they still lack few characteristics that challenges conventional leadership practice. Meta Principalism will somewhat throw spotlight on principal preparation for $21^{\text {st }}$ century which will be easily understandable by Nepalese private school principal.

\section{Concept of Meta Principalism}

In a simple meaning, "Meta" means changed or altered (Online etymology dictionary, 2015) hence Meta principal means "changed principal". From the analysis and theoretical interaction, I would like to propose my viewpoint that the simple concept to prepare themself. Hence my suggestion would be that principals prepare themselves and change through simple model following Meta Principalism. It is the capacity of principal to exercise control over one's own leadership style. It is enacted by principals as a way of ensuring the homeostatic balance of their sensor of change and acting towards the moulding process of leadership style. Unlike above mentioned Theorist perspective like transformational leadership theory and personal brand theory which leads to leading change, it is characterised by intentionality, forethought and selfreflectiveness. It is also characterised by deep self-knowledge based upon an informed understanding of personal strengths, weaknesses and capabilities; a knowledge that has been refined from deep self-reflection based on experiential learning that leads to environmental scanning of change and transforming accordingly. Few principles of Meta Principalism are:

- $\quad$ Self reflection

- Accelerating through quality education

- $\quad$ Offering new ways to think about school change

- $\quad$ Deconstruction of conventional mindsets

- Identifying ground-breaking leadership style

- $\quad$ New pedagogy for Principal: Leaders manage, mangers lead

- Allocating concrete method to prepare

Guiding theories for Meta Principalism: There is no one single opinion among authors to define how theories are developed and become effective so that it can be implemented in principal preparation process. The study of leadership began from early part of the twentieth century. That time the concern was what qualities make a person leader and what makes followers. In search of the queries on leadership a number of theories emerged gradually.

Great Man theories: This theory developed looking into the contributions of great people like Abraham Lincoln, Mahatma Gandhi, and Alexander the Great and Julius Caesar. Historian Carlyle (1888) is the founder of this theory. According to him there is divine power in them like god. According to Carlyle (1888), effective leaders have inherent capacity to solve problems. This theory assumes that the credibility for leadership is within leader themselves (inherent) which means that the leaders are born but not made. This theory also projects on their characteristics like daring, charismatic and meant to uphold to control whenever necessary. The model of Meta Principalism also thinks that principal are born leader and they can mold their leadership attributes according to their wish. 
Trait theories: Trait theories basically say that the leader is born with certain qualities and traits that make them best for the leadership role. Some traits such as aptitude, socio economic position, and child-education practices are of great value in the individual to become leaders. "This theory has identified six categories of personal factors associated with leadership: capacity, achievement, responsibility, participation, status, and situation. However he concluded that such a narrow characterization of leadership traits was insufficient and further stated that A person does not become a leader by virtue of the possession of some combination of traits" (Stogdill, 1948: p. 64). Meta Principalism poses questions when it is seen that persons having so called most important traits of personality and behavior are leaders.

Behavioral theories: Ohio State University (1940s) states that there two behaviors in leaders: People centric and task centric. Task structure is concerned with the preference of leaders towards the tasks of the subordinates. Employee oriented rather than how much tasks the followers and employee oriented is concerned with the understanding of followers problems why they are not been able to carry out their functions and taking remedial measures to develop them through the different developmental activities, like understanding the problems, coaching, counseling, mentoring, etc related to. University of Michigan (1950s) stated that task oriented is not preferred by the followers so employee oriented behavior is effective. Concept of Meta Principalism also believes that people can learn to become principal through self learning, self teaching and self observation more precisely self reflection.

Contingency theories: This theory assumes that in sometimes one style of leadership is effective and in other situations other styles so an effective leader cannot be effective in other situations (Fiedler, 1967) differentiating between leadership styles and behaviors, came to conclusion that leadership styles designate leaders' motivational system and that leadership behaviors are leaders' specific actions. He presented a model whether the leader should be task oriented or employee oriented based on the situations created by three conditions-relations with subordinates, initiating structures and his position and power. House's (1971) Path-Goal Theory included the interaction of leadership behaviors with situation characteristics in determining the leaders' effectiveness. This theory guides the concept of Meta Principalism to focus on specific variables related to the specific environment which determine any specific or particular style of leadership is best suited for the specific situation.

Situational theories: Situational theories focus on leader's ability to solve the problems differs in different situations so this circumstance decides one's leadership at the situations. Hencley (1973) reviewed leadership theories and indicated that leadership is determined not so much by the characters of the individuals as by the requirements of social situation. After that attempts were made to identify specific characteristics of a situation that affected leaders' performance. So, Hoy and Miskel (1987) listed four areas of situational leadership: (1) structural properties of the organization, (2) organizational climate, (3) role characteristics, and (4) subordinate characteristics. Meta Principalism is guided by the situational leadership that reveals the complexity of leadership but still proved to be insufficient because the theories could not predict which leadership skills would be more effective in certain situations. This theory further argues that all styles of leadership are effective but must be applied in proper situations where they will be fit.

Participative theories: Participative theories believe that people like the leaders if they are recognized at the time of decision-making. A participative leader seeks to involve the concerned members in decision making process. In Meta Principalism, participative leadership style guides most significant roles, because member's involvement and ownership at decision making process works as capsule to achieve the group goals.

Management theories: Management theories are known as transactional theories also which relies on the manager's ability to assess the performance of the followers, and rewarding them accordingly. The transactional style of leadership was developed and bought into action by Max Weber in 1947 and later by Bernard Bass in 1981. These theory stages on the strong base of rewards and punishments. Managerial theories teaches concept of Meta Principalism in the form of transactional relationship used in schools by rewarding efficient teachers and punishing and threatening inefficient teachers (when pass percent of the concern subject goes down). 
Relationship theories: Burns (1978) bought transformational leadership as relationship theories which is a process where leaders and followers work together mutually to bring each one at the front whit high level of integrity, motivation and morality. Burns' argued in favor of transformational leadership to be more effective than transactional leadership. According to Burns, transformational leadership can be seen when leaders and followers work together for the common goals with high level of trusting work culture; they recognize each other not on the basis of immediate benefit but on the basis of long lasting common benefit. This theory is the heart for Meta Principalism concept as it has a positive effect on the group. Ronald E. Riggio has indicated that groups led by transformational Principal have higher levels of performance and satisfaction than groups led by other types of leaders. The reason, he suggests, is that transformational leaders believe in empowering people for the best performance. Bass and Riggio (2008) have explained that transformational principal stimulate and inspire followers to both achieve extraordinary results and, during the process, enlarge their own leadership capacity.

Icing on the cake: Principal preparation syllabi for Meta Principalism: It is found in the research of Hess \& Kelly (2007) that principals often are taught coursework's besides the on the job methods of principal preparation and enables formation of Meta principal. These courses are classified into seven groups: managing results, managing personnel, technical knowledge, external leadership, norms and value, managing classroom and leadership and schools culture.

\begin{tabular}{|c|c|}
\hline Managing results & $\begin{array}{l}\text { "Accountability," "evaluation," "assessments," "data management," "decision- } \\
\text { making," "strategy," "organizational structure," and "change." }\end{array}$ \\
\hline Managing personnel & $\begin{array}{l}\text { "Recruitment," "selection," "induction," "teacher evaluation," "clinical supervision," } \\
\text { "motivation," "conflict management," "professional development," and } \\
\text { "termination" or "dismissal." }\end{array}$ \\
\hline Technical knowledge & $\begin{array}{l}\text { "school funding," "budgeting," "due process," "church and state," "student and } \\
\text { teacher freedoms," "tort law," "literature reviews," "sampling," "statistical analyses," } \\
\text { and "database management." }\end{array}$ \\
\hline Exter & $\begin{array}{l}\text { ool board relations, , parent and community relations, } \\
\text { eting and politics and policy }\end{array}$ \\
\hline Norms & $\begin{array}{l}\text { n," "multiculturalism," “diversity," "constructivism," } \\
\text { "equity," "social justice," and "gender." }\end{array}$ \\
\hline ng classroom & $\begin{array}{l}\text { "curriculum," "learning theories," "instructional leadership," "pedagogy," "classroom } \\
\text { management," and "collaborative learning" }\end{array}$ \\
\hline $\begin{array}{l}\text { Leadership and } \\
\text { schools culture }\end{array}$ & $\begin{array}{l}\text { "the frames of leadership," "symbolic leadership," } \\
\text { "Leadership vs. management," "creating a school culture," "leading with vision," and } \\
\text { "school climate." }\end{array}$ \\
\hline
\end{tabular}

\section{Application of Meta Principalism in Nepal}

I would like to purpose various ways which leads Nepalese private school principal to cope with change and new designs of trends are experimented. In order to enhance the prepared principal process through Meta Principalism, following principle are highly ad versed to support private school principal preparation and focus more on wellbeing of leadership process.

Self Reflection: Any leader goes through extensive experience of ups and downs in their work life. Successful principal always learn from others. Principal take all the information and calculates inside his mind, later he adds all those observation and tries to check with his acts. Self reflection always makes leader stronger and it is highly recommended to private school principal of Nepal to incorporate all the observation and manifest into better self reflection resulting better outcome.

Accelerating change towards Quality Education: Nowadays, quality education has been defined utmost pragmatic ways and been in the hypes of almost all educationist, government and private school of Nepal. Either amendment in governments' five or 10-year development plans; educational quality resulting from schools is measured mostly in economic terms and quantitative targets. In the dawn of globalization, educational quality is being calculated in the form of competitiveness of graduates in the global market. The 
embarkation of Quality education which I personally feel is done through school principal's skills and competencies that is showcased in their respective school. Many private schools in Nepal are lunching their progression chart through implication of ICTs programs. It is seen in many school that principal are gradually in the process of preparation for the knowledge-based, information society. In Nepalese private school too, principal slowly understand that students as human capital and are the major factor that helps in growing national economy. This is only possible when change is introduced to the school. I would like to also add that to bring the change, principal needs to be changed. Their priority should be placed on courses directly contributing them to the national own economic development goals and creating value based students.

Offering new ways to think about School Change: Delros (1998) put his opinion that the interest of many people involved in education sector is for the educational reform to employment and the economy of the country. It is in fact the force and urgency with which educational reform is politically advocated that give proper shape to schools in Nepal. The traditional monopoly, according to my viewpoints, private school principal had on education is giving way to various pressure groups that seek education to be used as an instrument in effecting their own agenda in Nepal. It is also be noted that the influence of these pressure groups is not only felt in the area of educational accountability and leadership practice but also on the structure of education systems, the organization and structure of schools, the content of curricula, and teaching methods of teachers. The driving forces that necessitate the introduction of change in Nepalese principal themselves is the easy acceptance of change in school. As the world changes, country changes, society changes resulting the change in education sector. No principal should be furious by the change process but fight against the change and come out with solution best for them and the school. The change process involves four levels, namely active initiation and participation, pressure and support, changes in behavior and beliefs, and ownership (Fullan, 1991). In the absence of the understanding of the difficult nature of the changes, and lacking of qualified, experienced and skilled development opportunities for principal of private school in Nepal, school can eventually stop adjusting with the new and innovative pedagogy if there is no change in school long tern vision and goal. The planning, execution, and assessment of principal preparation process needs to guarantee awareness in all the steps associated with the change procedure. Accountability is another stem that I feel should be the key word that backs the success of Principal Preparation Process and new paradigm of school change. Governments shall think of making a taskforce or committee that checks the performance of principal and balance the gaps during his working period. Parents have also become more sensitive than ever before about the quality of their children's education in schools which makes them a key actor to grease the school change process and let principal change too. Reform efforts that do not focus on present private school problem may fail. Therefore, Principal Preparation Process needs to change its importance from operational outbound setting to in-house simulation with principal in the direction of development of coaching, facilitating learning and school effectiveness. So, private school should focus on changing conventional formation of various rules, values and norms that school anticipates in order to enhance the successful presentation of principal.

Deconstruction of Conventional Leadership Mindsets: From my observation and interview on private school principal of Nepal I came to point that a single person with all his attributes is playing a leadership role in their respective school into which is built notions of competition and power (Thornton, 2005) and less likely to collaborate with other staffs through which are convinced nation of school best performance is known. Previously school leadership are often hierarchical and mostly authoritarian. This fairly top down formation was actually autocratic leadership style which was mostly liked in early days of private school in Asia with a gradual transformation towards distributive and transformational leadership that asserts to transform school's life and create value based organization. Role definition for private school principal in Nepal seems to be challenging especially in the early year's leadership. But I see one thing is common with early days and present time, before too principal were not academically and professionally sound to run school and vice versa. Mostly business person or entrepreneurs are the principal in private school principal of Nepal which always bring some kind of gap in leading and performing. My findings have already came up with the outcome that private school principal tend to be held by 'accidental leaders' with minimal training to carry out their responsibilities (Rodd, 2005). Rodd call for clear definitions of roles and lines of responsibility for principal, and in turn explore ways in which obstacles to effective leadership and management can be identified and overcome (Rodd, 2005). The Effective implementation of Preparation Principal Process in Nepal can create well-built association between the 'specification of the principal and actual qualitative 
service required by the school. Moreover lack of leadership training which I feel for private school principal is possible that they are considerably under-prepared for the post and to face the challenges from changes. Hence, deconstruction of old pedagogy in leading will help not only private school principal but also the overall effectiveness of their school.

Identifying ground breaking leadership style: Throughout the research, I found out that Nepalese principal loves change and experiment with their leading style keeping actual meaning of contingency approach and transformational leadership style into account. But mostly I observed that Nepalese private school principal do love change as well but scared of the consequences. They have fair knowledge of leadership style and their favourite quote is "I follow situational leadership style" with significant inclination towards "Transactional Leadership". Beare, Caldwell and Millikan (1993) on the note of school management distinguish between transactional and transformational leadership. Managers who are 'transactional' in their approach to school improvement try to 'sell' their ideas. Transformational managers, on the other hand, try to improve through improvising working condition, most notably the attributes of its staff (Beare et al., 1993). Depending on the kind of change, I feel that principal may demonstrate any leadership styles as per the convenience. It is seen that regardless of the fearful view of Nepalese private school principal, they act as the main 'change agent' in the school, by enhancing the attributes of staff through usual observation by staff, parents and student to understand and act on feedbacks as well as criticism. Only one place that lack is maintaining and providing sufficient in-service training, Meta principalism always on go for the training that enhances leadership style on oneself. Nepalese private school principal needs to act their image as "Political leader" who are in craved with "charisma". Individual charisma of the school principal may be a one of the key traits for school to achieve success, as well as bring partnership and dedication among staff. Many innovative leadership that can be utilized by school principal are the charismatic leadership aspect which add value to the overall success and performance of school.So they have understand clearly that if their school progress is published in local level, their leadership will be added advantage that stimulates school performance similar as meta principal suggest. So principal are the one who forecast and reacquire most innovative leadership style other than situational leadership style.

New Pedagogy for Principal: Managers lead and Leaders manage: It seems that principal in private school in Nepal is either getting into role of managers or leaders. I strongly argue that prepared principal always does things differently and create own pedagogy. To become prepared principal of today's world, that both leadership and management are important. Effective school principal can take both roles in a significant manner and according to the usage in their school. Therefore Meta principalism suggest that school principal should have both leadership and management skill, as both competences qualifies for the better future of school, and principals especially needs to practice lifelong learning for understanding competencies. The existence of either leadership or management skills makes school principal well versed to tackle every aspect in the school. Hence, Meta Principalism helps in applying the skills required by the school and school principal should be good at both leading and managing.

Allocating concrete methods for school principal preparation: For me change is growing and everything. Perhaps the greatest challenge for private school is to develop prepared principal for future-principal who leads with and through others, not over them. Meanwhile attributes of principal are shifting from very old nature of leadership to more situational and transformational, from conventional to more participative and power sharing, the challenge of molding concrete methods is really difficult task. To explore methods for school principal preparation for Nepal, that too may be leadership development program which is fairly conservative and slow to change, I came up with mainly three concrete methods which is applicable in Nepal.

- Expanding Learning Opportunities

- Succession Planning

- Ample training Prospect

- Formation of LDC.

It may be debated now how soon private sector or government awakens for the revolution to happen. Although there is a gradual transformation among Nepalese private school principal but not up to the mark of principal. I see that leadership shift guided by $21^{\text {st }}$ century. 
Expanding Learning Opportunities: Increased competitions in private sector have traced the necessity of learning opportunities either for the teachers or principal. I believe that learning is the one of the important step in becoming prepared principal. Promoting leadership by learning should be an essential motto of the private school principal. This is especially very true in the case of Nepalese private school principal who I feel has stopped gaining qualification after post graduation. In order to affect this, new strategies should be designed by the government policy or private school itself to set a margin for qualification which is mandatory for being a principal. Preparation of principal also requires lifelong learning, new information is piled day by day and to become effective principal, one has to be sound in learning all those piles. The obvious reason for this is that skills should constantly be renewed in the face of ever-changing technology. This calls for the development of new pedagogical provisions in Preparation of Principal Process in Nepal for principal in the higher learning institutions.

Succession Planning: Given the difficulties faced by many private school principals is what I feel in securing and then enacting their role, supporting the career development of staff is a key foundation for the future. They tend to establish school themselves but have a big fear of uncertainty for future successor. Since principals are created with proper preparation. Many private school principals should make efforts to identify and nurture talent in all their staff, especially when there is absence of second generation from principal's family. The effort to create future leader learners through identifying right talent and then training them is the easiest way of creating independence, particularly to avoid dependence on an uncertainty of school.

Ample Training Prospect: In The major disconnect that Nepalese private school principal faces when there is no adequate training program affiliated to the principalship, leadership or leading in change. Government too is the occasional player in conducting many traditional leadership development programs. I feel that government should be in high alert in providing ample training that are necessary for both private and public school principal which involves present leadership trend and practices. Private schools too, if they are hiring any principal for the job, they must encourage participants (current principal or successor) for such programs and fund them. Eventually, private organization in Nepal might also focus in creating customized and outbound training programs. If possible, it can also create and build Centre for Excellence where intensive training program related to Future principal goes on. In other words, they should act as "quick fix" to major problems and hurdles that occur in the course of running school effectively.

Formation of $\boldsymbol{L D C}$ : I strongly argue that Nepalese education sector is really in need of "Leadership Development Centre" either by the assistance of government or principal association or jointly. Leadership Development Centre is very progressive and involves in principal training and development. LDC can cater both public and private sector personals including teachers and principals. Expert trainers will have chance to interact with the school leader in order to change principal cognitive behavior. Private school principal may get benefited with programs that can address personal challenges to become a prepared principal. LDC helps principal in cognitive learning and focuses on behavioral transformation which will create school effectiveness through better leading.

\section{Conclusion}

The claim I made for Meta Principalism suggest that principals will manifest school vision in order to create best performance of school with all the factors I have mentioned above. In the process of continuous improvement school vision, transformative school leadership which values in creating transformative school vision are most evaluated and considered these days. The major principal practice I found out that distinguishes prepared principal to non prepared is that principals provide opportunities for transformative ideas to be explicitly discussed as the school culture which is being developed and in the case of larger community involvement, intentional inclusion of society, parents, teachers and students. It is clear that time is changing in fast motion. The focus on new development, paradigm shift in leadership practices and effective way of running school shall not to be missed as changes occur. With the help of sharp intelligence and guidance turmoil can be eradicated in snap of fingers. Nepal is developing country and I think it should learn so many things from so many developed countries to make itself into a gradual progression. Education sector is one of the aspect where Nepal can study various developmental prospects from others countries. 
Principal focusing on Meta principalism forecast and plans all the course of action that entitles principal to reciprocate changes that are seen in the school and educational sphere. I strongly proceed with the statement that the future of private school demands principal focusing on simple guiding principal of Meta Principalism who can loosen up all their conventional leadership style and embrace their own personal leadership brands, who also knows the role of leader and manger and finally act as a "Transformer". They also need to be able to influence through their personal leadership and to improve their Meta Principalism to enhance their leadership skills and leading through change. Emerging ideas from principal of developed countries gives ample example on simple steps of Meta Principalism to become Effective and efficient principal for future school change. Those principal can be changed with the incorporation of various principle of Meta Principalism and change the way they approach to their work, their environment, and each other.

\section{Reference}

Bass, B. M. \& Riggio, R. E. (2008). Transformational Leadership. Mahwah, New Jersey: Lawrence Erlbaum Associates, Inc.

Beare, H., Caldwell, B. \& Millikan, R. (1993). Leadership in: Preedy, M. (Ed); Managing the Effective School; London: Chapman

Burns, J. (1978). Leadership. New York: Harper \& Row.

Carlyle, T. (1888). On Heroes, Hero-Worship and the Heroic in History, Fredrick A. Stokes \& Brother, New York.

Conner, D. R. (1995). Managing at the speed of change: How resilient managers succeed and prosper where others fail. New York: Villard Books.

Delros, J. (1998). Education; Issues and Prospects. France: UNESCO Publishing

Fiedler, F. (1967). A Theory of Leadership Effectiveness. New York: McGraw-Hill Companies, Inc.

Fullan, M. G. (1991). The new meaning of educational change. New York: Teachers College Press.

Fullan, M. (1993). Change forces: Probing the depths of educational reform. London: Falmer Press.

Hargreaves, D. ( 1999) Helping School Practitioners Explore their School's Culture, in J. Prosser (Ed.), School Culture, London: Paul Chapman.

Hencley, S. P. (1973). Situational behavioral approach to the study of educational leadership. In L. C. Cunningham \& W. J. Gephart (Eds.), Leadership: The Science and Art Today (pp. 139-164). Itasca, IL: F.E.Peacock Publishers.

Hess, F. M. \& Kelly, A. P. (2007). Learning to lead: What gets taught in principal-preparation programs [Electronic version]. Teachers College Record, 109(1), 244-274.

House, R. (1971). A path-goal theory of leader effectiveness. Administrative Science Leadership Review, 16(2).

Hoy, W. \& Miskel, C. (1987). Educational Administration. New York: Random House.

Kotter, J. P. (1996). Leading Change, Boston, MA: Harvard Business School Press.

Meaning of Meta. (2015). In Online Etymology Dictionary. Retrieved January 15, 2015, from http://www.etymonline.com/index.php?term=meta

Rodd, J. (2005). Leadership in Early Childhood (3rd edition), Maidenhead: Open University Press

Stogdill, R. M. (1948). Handbook of leadership: A survey of the literature. New York: Free Press.

Thornton, K. R. (2005). Courage, Commitment and Collaboration: Notions of Leadership in the New Zealand ECE 'Centres of Innovation', Victoria: University of Wellington (unpublished M.Ed thesis) 